\title{
A method on hydrogen permeation measurement through steel under constant tensile stress
}

Guo $Y i^{*}$

School of Materials Science and Engineering, Jiangsu University of Science and Technology, Zhenjiang 212003, China

*E-mail: 503733642@qq.com

doi: $10.20964 / 2017.09 .41$

Received: 29 March 2017 / Accepted: 6 July 2017 / Published: 13 August 2017

Hydrogen permeation behavior was studied by many researchers, uniaxial tensile stress may affect the behavior due to the deformation of specimen. However, less study focused on hydrogen permeation behavior during Slow Strain Rate Test (SSRT). In order to clarify elastic and plastic deformation effect on hydrogen permeation, hydrogen permeation behavior was measured by D-S double cell during SSRT in this study. The results show that the background current density increases in elastic deformation range during SSRT due to the damage of thin Ni coating. Hydrogen permeation current density increases slowly in elastic deformation range and decrease quickly in plastic range. The main reason of Hydrogen permeation current density decrease is trapping effect of dislocations that was formed in plastic deformation. Hydrogen permeation current density was affected by the competition mechanism between dislocation trapping and dislocation transport of hydrogen.

Keywords: hydrogen permeation measurement, SSRT, elastic deformation, plastic deformation

\section{$\underline{\text { FULL TEXT }}$}

(C) 2017 The Authors. Published by ESG (www.electrochemsci.org). This article is an open access article distributed under the terms and conditions of the Creative Commons Attribution license (http://creativecommons.org/licenses/by/4.0/). 